\title{
Antitumor effect and antiangiogenic potential of the mTOR inhibitor temsirolimus against malignant pleural mesothelioma
}

\author{
MAKIO MORIYA $^{1}$, TADAAKI YAMADA ${ }^{2}$, MASAYA TAMURA ${ }^{1}$, DAISUKE ISHIKAWA ${ }^{2}$, \\ MIR ALIREZA HODA ${ }^{3}$, ISAO MATSUMOTO ${ }^{1}$, WALTER KLEPETKO ${ }^{3}$, \\ MAKOTO ODA $^{1}$, SEIJI YANO ${ }^{2}$ and GO WATANABE ${ }^{1}$ \\ ${ }^{1}$ Department of General and Cardiothoracic Surgery, ${ }^{2}$ Division of Medical Oncology, Cancer Research Institute, \\ Kanazawa University, Kanazawa, Japan; ${ }^{3}$ Department of Thoracic Surgery, Medical University of Vienna, Vienna, Austria
}

Received September 21, 2013; Accepted November 12, 2013

DOI: $10.3892 / o r .2013 .2948$

\begin{abstract}
The mTOR inhibitor temsirolimus has antitumor and antiangiogenic activity against several carcinomas, yet few reports document the efficacy of temsirolimus against malignant pleural mesothelioma (MPM). Therefore, we evaluated the efficacy of temsirolimus and the antiangiogenic effect of temsirolimus in the treatment of MPM. We examined the efficacy of temsirolimus alone and the efficacy of the combination of temsirolimus and cisplatin or pemetrexed against four MPM cell lines using the 3-(4,5-dimethylthiazol-2-yl)-2,5-diphenyl tetrazolium bromide (MTT) assay. The effect of temsirolimus on the production of proangiogenic cytokines by MPM cell lines was examined by enzyme-linked immunosorbent assay (ELISA). Expression of mTOR and proangiogenic cytokines in clinical specimens from MPM patients was determined by immunohistochemistry. Temsirolimus inhibited cell viability and suppressed cell proliferation of all MPM cell lines. Combined treatment with temsirolimus and cisplatin inhibited the viability of all MPM cell lines more effectively than temsirolimus alone. Temsirolimus strongly inhibited the phosphorylation of p70s6k, a downstream molecule of mTOR, in all MPM cell lines and led to an increase in the levels of cleaved caspase-3 in the H226 and Y-meso14 cells. Temsirolimus also inhibited the production of vascular endothelial growth factor (VEGF) and platelet-derived growth factor-AA (PDGF-AA). Phosphorylated mTOR and high expression of VEGF and PDGF were detected in 2 and 3 , respectively, out of the 5 MPM specimens. These results suggest that temsirolimus has activity against MPM cells by inhibition of cell proliferation and angiogenesis, and may be beneficial for a subset of MPM patients with high mTOR expression.
\end{abstract}

Correspondence to: Dr Masaya Tamura, Department of General and Cardiothoracic Surgery, Kanazawa University School of Medicine, Takara-machi 13-1, Kanazawa 920-8640, Japan

E-mail: masatamu2007@yahoo.co.jp

Key words: mesothelioma, mammalian target of rapamycin, temsirolimus, antiangiogenesis

\section{Introduction}

Malignant pleural mesothelioma (MPM) is an aggressive cancer arising from the surface serosal cells of pleural cavities. MPM is associated with exposure to asbestos fibers. MPM is highly resistant to conventional chemotherapy and radiotherapy, and has an extremely poor prognosis; median survival is 4-13 months for untreated patients (1) and 6-18 months for treated patients $(2,3)$. Although platinum-based chemotherapy is used widely, it has a modest therapeutic effect. Hence, identification of new agents that enhance its therapeutic effect is warranted.

The mammalian target of rapamycin (mTOR) is a $289-\mathrm{kDa}$ serine-threonine kinase that was identified as a target molecule of rapamycin (a macrolide fungicide isolated from the bacteria Streptomyces hygroscopicus). mTOR is a member of the large phosphatidylinositol 3-kinase (PI3K)-related kinase (PIKK) family of protein kinases, and is located downstream of the PI3K/Akt signaling pathway. Growth factors such as insulinlike growth factor (IGF), epidermal growth factor (EGF) and vascular endothelial growth factor (VEGF) regulate mTOR signals through the PI3K/Akt signaling pathway (4). Rapamycin inhibits mTOR by binding to its immunophilin, FK506-binding protein 12 (FKBP12), and blocks progression from the $G_{1}$ phase to the $S$ phase of the cell cycle and induces the apoptosis of tumor cells (5). mTOR also plays a key role in angiogenesis. mTOR increases the translation of hypoxia-inducible factor 1 (HIF-1)/HIF-2. A major role of the HIF transcription factors is to upregulate transcription of mitogenic growth factors such as VEGF which lead to angiogenesis (6).

Temsirolimus, a water-soluble dihydroester analog of rapamycin, has been approved for renal cell carcinoma and breast cancer, based on the results of a randomized phase III study (7) and a phase II study (8), respectively. Recent studies have demonstrated that mTOR inhibitors are useful for the treatment of MPM $(9,10)$. Several studies have suggested that temsirolimus inhibits angiogenesis through inhibition of HIF-1-dependent VEGF production in breast cancer and multiple myeloma $(6,11)$.

In the present study, we evaluated the benefits of temsirolimus against MPM cell lines and the efficacy of combination 
therapy with cisplatin or pemetrexed (which are presently used as therapeutic agents for MPM) and assessed the antiangiogenic effect of temsirolimus against MPM in vitro.

\section{Materials and methods}

Cell lines and culture conditions. The MPM cell lines H290 and Y-mesol4 as well as the human mesothelial cell line Met-5A were kindly provided by Dr Sekido (Aichi Cancer Center Research Institute, Nagoya, Japan). The MPM cell lines $\mathrm{H} 226$ and MSTO-211H as well as the human lung fibroblast cell lines MRC-5 and IMR-90 were purchased from the American Type Culture Collection (ATCC; Manassas, VA, USA). Cells were maintained in specific media during incubation at $37^{\circ} \mathrm{C}$ in a humidified atmosphere of $5 \% \mathrm{CO}_{2}$ in air. Four human MPM cell lines and MeT-5A were cultured in RPMI-1640 medium supplemented with $10 \%$ fetal bovine serum (FBS). MRC-5 and IMR-90 were cultured in Dulbecco's modified Eagle's medium (DMEM) with $10 \%$ FBS. Each medium contained $100 \mathrm{U} / \mathrm{ml}$ of penicillin and $0.1 \mathrm{mg} / \mathrm{ml}$ of streptomycin.

Drugs. Temsirolimus was obtained from Pfizer (New York, NY, USA), cisplatin was from Nippon Kayaku (Tokyo, Japan), and pemetrexed was from Eli Lilly (Tokyo, Japan). Temsirolimus was stored as a 1-mM solution in dimethyl sulfoxide (DMSO) at $-20^{\circ} \mathrm{C}$, cisplatin was stored as an undiluted solution $(0.5 \mathrm{mg} / \mathrm{ml})$ at $-20^{\circ} \mathrm{C}$, and pemetrexed was stored as a solution of concentration $1 \mathrm{mg} / \mathrm{ml}$ in physiological $(0.9 \%)$ saline at $-20^{\circ} \mathrm{C}$.

Cell viability and proliferation assays. Cell viability was measured by the 3-(4,5-dimethylthiazol-2-yl)-2,5-diphenyl tetrazolium bromide (MTT) dye reduction method (12). In brief, cells were seeded onto 96 -well plates $(2,000$ cells/well) in $100 \mu 1$ RPMI-1640 or DMEM with $10 \%$ FBS for $24 \mathrm{~h}$. Afterward, the cells were exposed either to temsirolimus alone (at concentrations ranging from 0 to $10 \mu \mathrm{M}$ ), cisplatin $(0-10 \mu \mathrm{g} / \mathrm{ml})$ or pemetrexed $(0-10 \mu \mathrm{g} / \mathrm{ml})$ for $72 \mathrm{~h}$ at $37^{\circ} \mathrm{C}$ with $5 \% \mathrm{CO}_{2}$ or combinations of the agents. In addition, $50 \mu \mathrm{l}$ of a stock MTT solution $(2 \mathrm{mg} / \mathrm{ml})$ was added to all of the wells, and the cells were incubated for $2 \mathrm{~h}$ at $37^{\circ} \mathrm{C}$ with $5 \% \mathrm{CO}_{2}$. The media containing the MTT solution were removed and the dark-blue crystals dissolved by adding $100 \mu$ l DMSO. Absorbance was measured at a wavelength of $570 \mathrm{~nm}$ with a microplate reader. Cell proliferation was determined by cell counting. Cells were seeded onto 6 -well plates $(10,000$ cells/ well) and incubated for the indicated periods. After cells were harvested, the cell number was counted.

Determination of protein levels of VEGF and platelet-derived growth factor-AA (PDGF-AA). Culture supernatants were evaluated. For culture supernatants, tumor cells were seeded into 6-well plates at $2 \times 10^{5}$ cells/well in $2 \mathrm{ml}$ of RPMI-1640 medium with $10 \%$ FBS and exposed to temsirolimus $(0-1 \mu \mathrm{M})$ for $48 \mathrm{~h}$. The supernatants were harvested, and the levels of VEGF and PDGF-AA were determined using enzymelinked immunosorbent assay (ELISA) kits (R\&D Systems, Minneapolis, MN, USA) according to the manufacturer's instructions. The lower limit of detection was $31.2 \mathrm{pg} / \mathrm{ml}$ for VEGF and $31.2 \mathrm{pg} / \mathrm{ml}$ for PDGF-AA.
Antibodies and western blot analyses. Tumor cells were incubated in $10 \mathrm{ml}$ of RPMI-1640 buffer with 10\% FBS in temsirolimus $(0-1 \mu \mathrm{M})$ for $1 \mathrm{~h}$. The total protein level was measured using a bicinchoninic acid (BCA) protein assay kit (Pierce Biotechnology, Rockford, IL, USA). For western blot analyses, $40 \mu \mathrm{g}$ of total protein was resolved by sodium dodecyl sulfate-polyacrylamide gel electrophoresis (SDS-PAGE) (Bio-Rad Laboratories, Waltham, MA, USA). The proteins were transferred onto polyvinylidene difluoride membranes (Bio-Rad Laboratories). The following primary antibodies were used: anti-phospho-S6 ribosomal protein; anti-S6 ribosomal protein, or anti-cleaved caspase 3 (Asp175) antibodies (1:1,000 dilution; Cell Signaling Technology, Beverly, MA, USA) and anti-G3PDH polyclonal antibody (1:1,000 dilution; Trevigen, El Paso, TX, USA). Membranes were incubated for $1 \mathrm{~h}$ at room temperature with species-specific horseradish peroxidase-conjugated secondary antibodies. Immunoreactive bands were visualized with SuperSignal West Dura Extended Duration Substrate Enhanced Chemiluminescent Substrate (Pierce Biotechnology). Each experiment was carried out independently in triplicate.

Immunohistochemical analyses. Five tumor specimens were obtained from 5 MPM patients, all of whom provided written informed consent, at the Kanazawa University Hospital. The present study was approved by the Institutional Review Boards of the Kanazawa University.

Paraffin sections were autoclaved and immunostained with the following primary antibodies: mTOR (mTOR/FRAP; rabbit monoclonal; 1:350 dilution; Epitomics, San Francisco, CA, USA), anti-phospho-mTOR [mTOR/FRAP phospho (pS2448); rabbit monoclonal; 1:100 dilution; Epitomics], anti-VEGF (rabbit polyclonal; 1:100 dilution; Santa Cruz Biotechnology, Santa Cruz, CA, USA), and anti-PDGF-AA (rabbit polyclonal; 1:200 dilution; EMD Millipore Corp., Waltham, MA, USA). Antibodies were visualized by a ChemMate EnVision/ peroxidase complex kit (Dako, Tokyo, Japan). The 'immunohistochemical expression level' was scored by a three-tier system: negative expression (score 0 ), $<10 \%$; low expression (score 1 ), $\geq 10 \%$ but $<50 \%$; high expression (score 2 ), $\geq 50 \%$ tumor cells with 'significant' staining (13).

Statistical analyses. Statistical analyses were carried out using GraphPad Prism ver 5.02. The statistical significance of differences between control and test values was analyzed using Student's t-test, Mann-Whitney U test, and one-way analysis of variance (ANOVA) with Bonferroni's post hoc test, where applicable. Differences at $\mathrm{P}<0.05$ were deemed significant.

\section{Results}

Effects of temsirolimus, cisplatin or pemetrexed on MPM cell lines. Temsirolimus treatment for $72 \mathrm{~h}$ inhibited the viability of all MPM cell lines in a concentration-dependent manner (Fig. 1A). The half-maximal inhibitory concentration $\left(\mathrm{IC}_{50}\right)$ of temsirolimus in H226, H290, Y-mesol4 and MSTO-211H cells was $\sim 2,0.5,0.5$ and $0.2 \mu \mathrm{M}$, respectively. Temsirolimus also inhibited the cell numbers of all MPM cell lines tested (Fig. 2), indicating that temsirolimus suppressed cell proliferation of the MPM cell lines. Cisplatin also inhibited the 

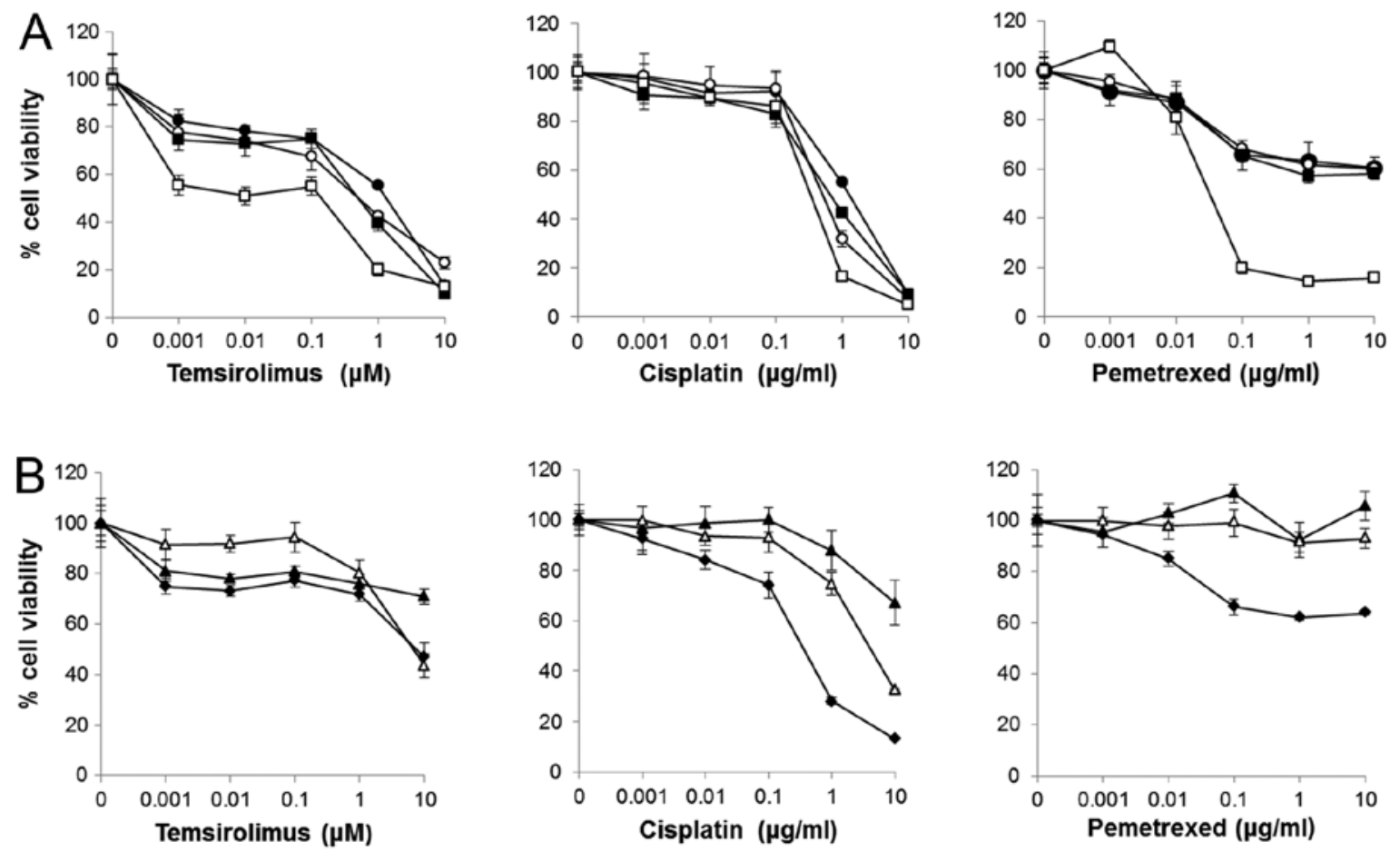

Figure 1. Effect of temsirolimus, cisplatin, and pemetrexed on the viability of MPM cell lines and non-neoplastic cells. (A) H226 (•), H290 (०), Y-meso14 (•) and MSTO-211H (ㅁ) $\left(2 \times 10^{3} /\right.$ well) cells were incubated for $72 \mathrm{~h}$ with temsirolimus $(0-10 \mu \mathrm{M})$, cisplatin $(0-10 \mu \mathrm{g} / \mathrm{ml})$ or pemetrexed $(0-10 \mu \mathrm{g} / \mathrm{ml})$. (B) MRC-5 (ه), IMR-90 ( $\Delta)$ and Met-5A ( $\bullet)\left(2 \times 10^{3} /\right.$ well $)$ cells were incubated for $72 \mathrm{~h}$ with temsirolimus $(0-10 \mu \mathrm{M})$, cisplatin $(0-10 \mu \mathrm{g} / \mathrm{ml})$, or pemetrexed $(0-10 \mu \mathrm{g} / \mathrm{ml})$ Points, mean of quintet cultures; bars, SD.
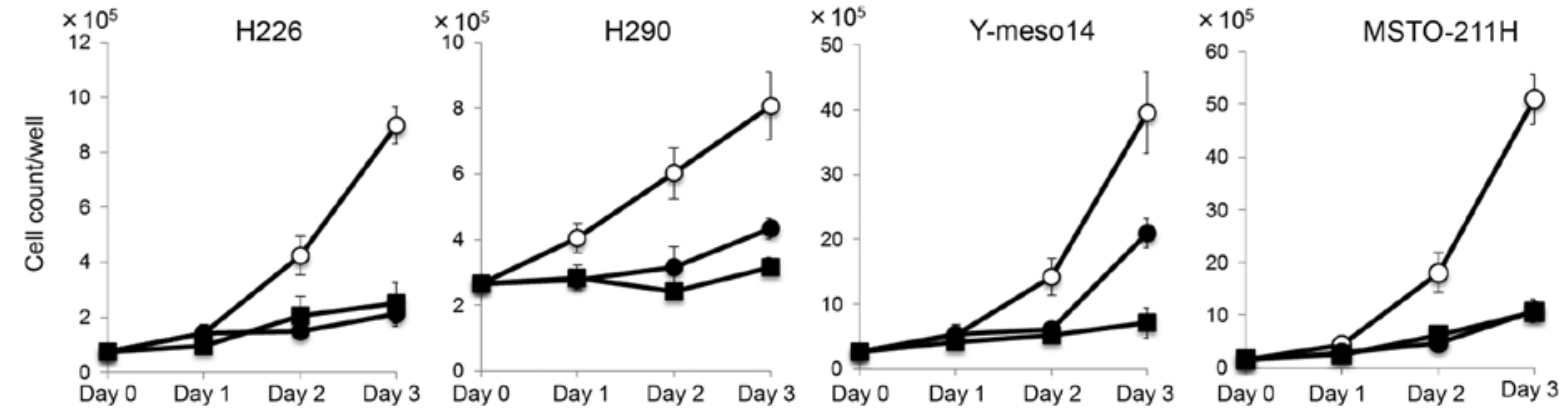

Figure 2. Effect of temsirolimus on the proliferation of MPM cell lines. MPM cell lines were incubated for the indicated periods with or without temsirolimus (control, $\circ ; 10 \mathrm{nM}, \bullet ; 100 \mathrm{nM}, \boldsymbol{\bullet}$ ). After cells were harvested, the cell number was counted. Points, mean of quintet cultures; bars, SD.

viability of all MPM cell lines. The $\mathrm{IC}_{50}$ of cisplatin in $\mathrm{H} 226$, H290, Y-meso14 and MSTO-211H cells was $\sim 2,0.5,0.7$ and $0.4 \mu \mathrm{g} / \mathrm{ml}$, respectively. Pemetrexed moderately inhibited the viability of MPM cell lines when compared with the effect of the other two drugs except for MSTO-211H cells. The $\mathrm{IC}_{50}$ of pemetrexed in MSTO- $211 \mathrm{H}$ cells was $\sim 0.04 \mu \mathrm{g} / \mathrm{ml}$, whereas it was $>10 \mu \mathrm{g} / \mathrm{ml}$ in the other three cell lines.

Effect of temsirolimus, cisplatin or pemetrexed on MRC-5, IMR-90 and Met-5A as 'non-neoplastic cells'. Temsirolimusinduced inhibition of the viability of non-neoplastic cells was less compared with that of the MPM cell lines (Fig. 1B). Cisplatin displayed strong inhibition of the viability of Met-5A cells, but less inhibition of the other cell lines. Pemetrexed showed slight inhibition of the viability of Met-5A cells, but not MRC-5 or IMR-90 cells.
Effects of a combined treatment of temsirolimus and cisplatin or the combined treatment of temsirolimus and pemetrexed on the viability of MPM cell lines. To examine the effect of temsirolimus combined with cisplatin or pemetrexed on MPM cell lines, cells were cultured with combinations of temsirolimus $(0-10 \mu \mathrm{M})$ and cisplatin $(0.1$ and $0.3 \mu \mathrm{g} / \mathrm{ml})$ or pemetrexed $(0.1$ and $0.3 \mu \mathrm{g} / \mathrm{ml}$ ) for $72 \mathrm{~h}$. MSTO-211H cells demonstrated high sensitivity to pemetrexed, thus the MSTO-211H cell line was excluded from combination treatment with temsirolimus and pemetrexed. The dose-response curves of the combination treatment are depicted in Fig. 3A. Combination treatment with temsirolimus and cisplatin inhibited the viability of all MPM cell lines more effectively than temsirolimus alone. When the effect of the combination treatment of $0.01 \mu \mathrm{M}$ temsirolimus and $0.3 \mu \mathrm{g} / \mathrm{ml}$ cisplatin was compared with $0.01 \mu \mathrm{M}$ temsirolimus alone or $0.3 \mu \mathrm{g} / \mathrm{ml}$ cisplatin alone, the combination 

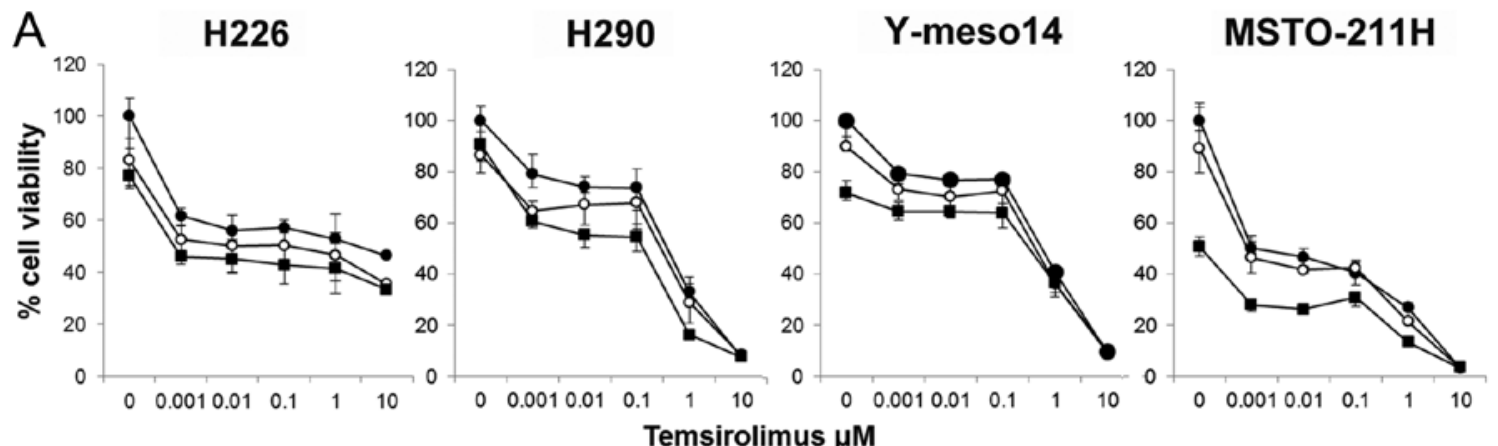

$\mathrm{B}$ H226
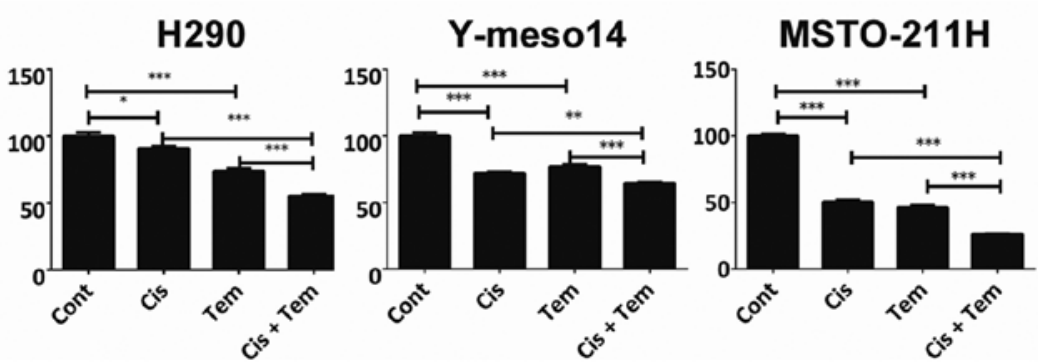

Figure 3. Effects of temsirolimus combined with cisplatin or pemetrexed upon proliferation of MPM cell lines. (A) MPM cell lines were incubated for $72 \mathrm{~h}$ with temsirolimus $(0-10 \mu \mathrm{M})$ and cisplatin $(0.1$ or $0.3 \mu \mathrm{g} / \mathrm{ml})$. Cisplatin-free $(\bullet), 0.1 \mu \mathrm{g} / \mathrm{ml}$ cisplatin (o), $0.3 \mu \mathrm{g} / \mathrm{ml}$ cisplatin ( $\bullet$ ). (B) Combination of temsirolimus (Tem) $(0.01 \mu \mathrm{M})$ and cisplatin (Cis) $(0.3 \mu \mathrm{g} / \mathrm{ml})$ in MPM cell lines. The significance of the difference between the control and test values was determined by the two-tailed multiple t-test with Bonferroni correction following ANOVA (three comparisons in four groups). Columns, mean of quintet culture; bar, SD; ${ }^{*} \mathrm{P}<0.05,{ }^{* *} \mathrm{P}<0.01,{ }^{* * * *} \mathrm{P}<0.001$.
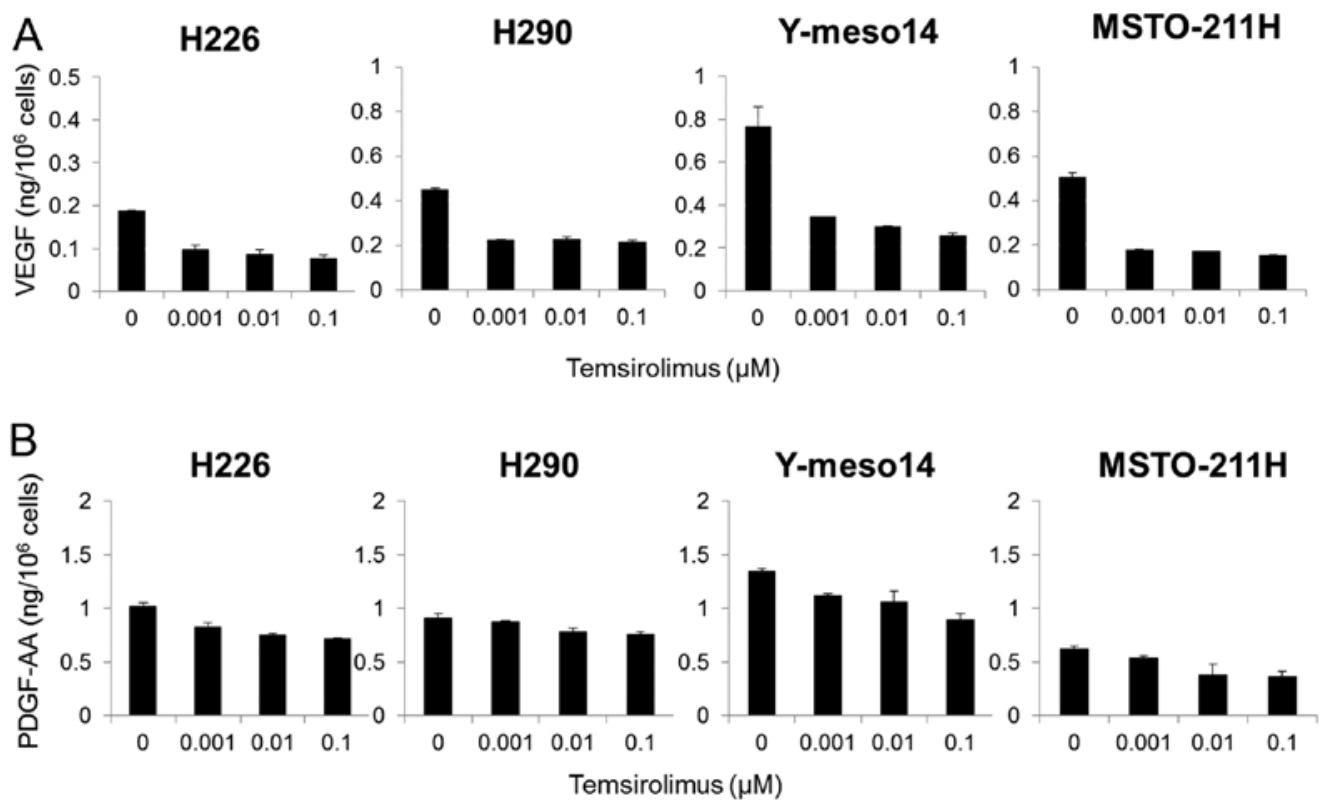

Figure 4. Effect of temsirolimus on the production of proangiogenic cytokines in MPM cell lines. (A) VEGF protein secretion by MPM cell lines as measured by ELISA. (B) PDGF-AA protein secretion by MPM cell lines as measured by ELISA. Columns, mean of representative of three independent experiments with similar results; bars, SD.

treatment was significantly more effective wheb compared with each drug alone in all MPM cell lines (Fig. 3B). There was no significant difference between the combination treatment of $0.01 \mu \mathrm{M}$ temsirolimus and $0.3 \mu \mathrm{g} / \mathrm{ml}$ pemetrexed with pemetrexed alone in the $\mathrm{H} 226$ cells or with temsirolimus alone in the $\mathrm{H} 290$ cells (data not shown). Compared with each drug alone, the combination of temsirolimus and pemetrexed was more effective only in the Y-mesol 4 cells.
Effect of temsirolimus on proangiogenic cytokine production in the MPM cell lines. To examine the effect of temsirolimus on the release of proangiogenic cytokines in the MPM cell lines, tumor cells were exposed to temsirolimus $(0-1 \mu \mathrm{M})$ and the levels of VEGF and PDGF-AA in the supernatants were measured by ELISA. Temsirolimus strongly inhibited VEGF production (Fig. 4A), and moderately inhibited the production of PDGF-AA in all four MPM cell lines (Fig. 4B). 


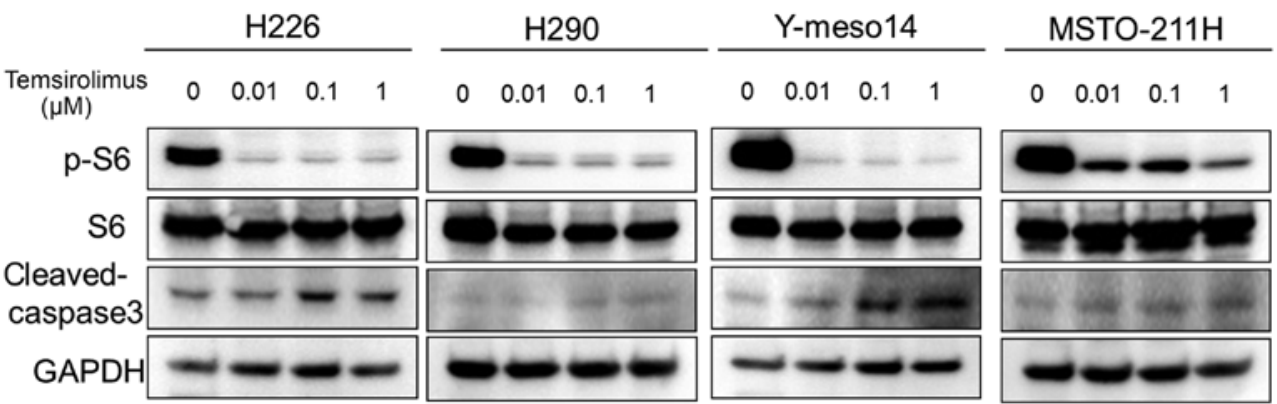

Figure 5. Western blot analyses of the downstream proteins of mTOR signaling after incubation of MPM cell lines with temsirolimus. MPM cell lines were incubated with temsirolimus $(0-1 \mu \mathrm{M})$ for $1 \mathrm{~h}$. G3PDH polyclonal antibody served as a loading control.
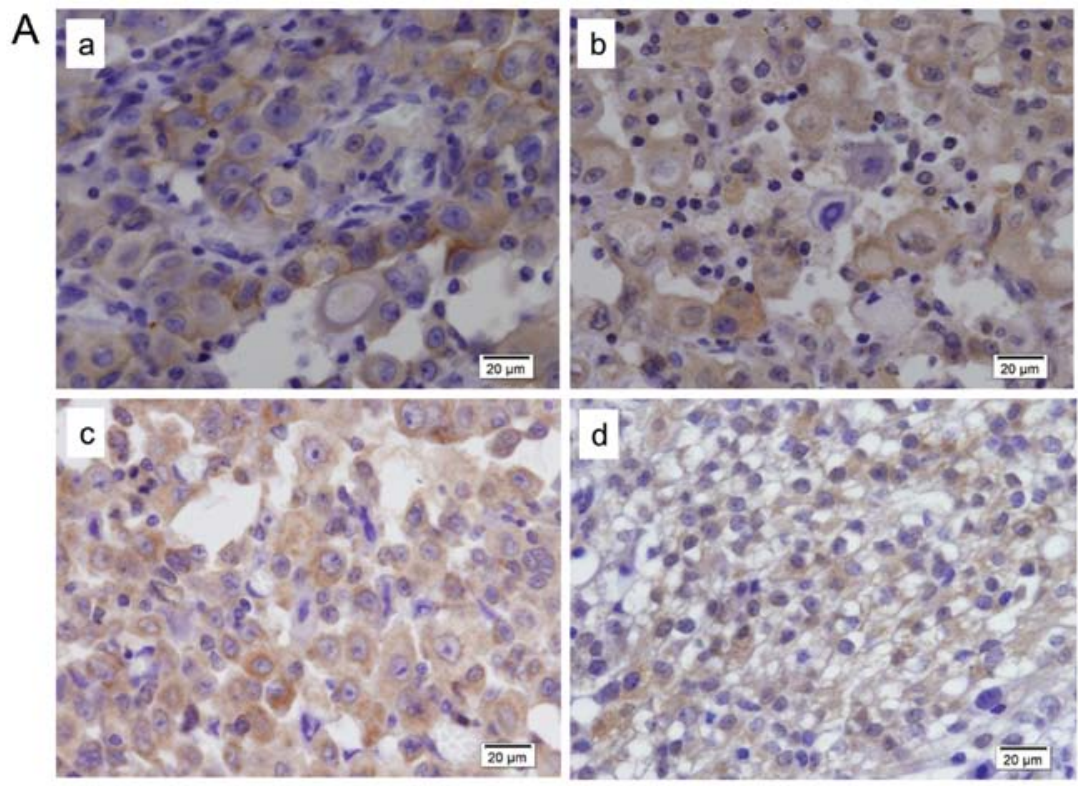

\begin{tabular}{|l|l|c|c|c|c|}
\hline & Type & mTOR & p-mTOR & VEGF & PDGF-AA \\
\hline Case.1 & Epithelial & 2 & 0 & 2 & 0 \\
\hline Case.2 & Epithelial & 0 & 0 & 2 & 2 \\
\hline Case. 3 & Epithelial & 2 & 2 & 2 & 2 \\
\hline Case.4 & Epithelial & 0 & 0 & 0 & 1 \\
\hline Case. 5 & Epithelial & 2 & 1 & 1 & 1 \\
\hline & negative expression: $<10 \%$ & score 0 & \\
& low expression: & $10 \%-50 \%$ & score 1 & \\
& high expression: & $50 \%<$ & score 2 &
\end{tabular}

Figure 6. (A) Immunohistochemical expression of mTOR (a), p-mTOR (b), VEGF (c), and PDGF-AA (d) in MPM tissues. (B) Summary of immunohistochemical expression of mTOR, p-mTOR, VEGF and PDGF-AA in MPM tissues. The immunohistochemical reaction was evaluated according to the extent of positive staining using the following score: negative expression (score $0,<10 \%$ positive cells); low expression (score 1, 10-50\% positive cells); high expression (score $2,>50 \%$ positive cells).

Effect of temsirolimus on the downstream proteins of mTOR signaling. Western blot analyses showed that temsirolimus strongly inhibited the phosphorylation of S6 ribosomal protein (a kinase regulated by mTOR). The level of cleaved caspase-3 (a known marker of apoptosis) increased in a dose-dependent manner in the $\mathrm{H} 226$ and Y-meso14 cells, but not in the MSTO211H and $\mathrm{H} 290$ cells, following treatment with temsirolimus (Fig. 5).
Immunohistochemical expression of mTOR, p-mTOR, $V E G F$ and PDGF-AA in MPM tissues. mTOR immunohistochemical staining exhibited an appreciable expression and cytoplasmic staining pattern in three of five MPM tissues (Fig. 6A-a and B). p-mTOR immunohistochemical staining also demonstrated a cytoplasmic pattern, and was observed in two of five MPM tissues (Fig. 6A-b and B). VEGF and PDGF-AA were expressed in the cytoplasm of numerous cells 
and in the nuclei of some cells in four of five MPM tissues (Fig. 6A-c, d and B).

\section{Discussion}

In the present study, we demonstrated that temsirolimus inhibited the proliferation of MPM cells and that combined treatment with temsirolimus and cisplatin (a standard chemotherapeutic agent for MPM) resulted in greater cell death in the MPM cell lines.

Temsirolimus is a water-soluble dihydroester analog of rapamycin and is being developed for the treatment of cancer. Temsirolimus was approved by the US Food and Drug Administration (FDA) for the treatment of advanced renal cell carcinoma (RCC) in 2007 as efficacy and safety were demonstrated at a second interim analysis of a phase III, multicenter, international, randomized and open-label study (7). In addition to RCC, several clinical trials were conducted in diverse types of carcinoma, such as breast cancer (8) and glioblastoma (14).

Several reports have focused on the effect of mTOR inhibitors on MPM. Hartman et al (9) demonstrated that sirolimus (previously known as rapamycin) inhibited the proliferation of MPM cell lines, and that a combined treatment of sirolimus and cisplatin led to greater cell death in MPM cell lines. Hoda et al (10) reported that temsirolimus attenuated MPM cell growth in vitro and tumor formation in vivo, and it synergized with cisplatin against MPM models in vitro and in vivo.

mTOR is a protein kinase located downstream of the PI3K/Akt signaling pathway, which has an important role in the survival and proliferation of cells. Temsirolimus gains function by binding to FKBP12 and this complex inhibits mTOR kinase activity, consequently inhibiting phosphorylation of the $40 \mathrm{~S}$ ribosomal protein S6 kinase (p70s6k) and the eukaryotic initiation factor 4E-binding protein-1 (4E-BP1) (15). Inhibition of these elements results in a decrease in protein synthesis and translation of specific mRNA species, and interferes with the progression from the $G_{1}$ phase to $S$ phase of the cell cycle (5). Temsirolimus also inhibits the translation of HIF-1/HIF-2, which upregulate the transcription of mitogenic growth factors such as VEGF and PDGF (6). In western blot analysis, phosphorylation of mTOR was observed in MPM specimens and temsirolimus strongly inhibited the phosphorylation of p70s6k (which is located downstream of mTOR) in all MPM cell lines in a dose-dependent manner. These data suggest that temsirolimus treatment inhibits the proliferation of tumor cells by inhibiting the phosphorylation of mTOR by inhibiting the activity of mTOR kinase. Temsirolimus treatment led to an increase in the level of cleaved caspase-3 (considered to be a marker of apoptosis) in $\mathrm{H} 226$ and Y-meso14 cells, but did not lead to an increase in the H290 and MSTO-211H cells. On the other hand, MTT assay showed that MSTO-211H cells had the most sensitivity to temsirolimus treatment. These data indicate that, in MSTO-211H and H290 cells, temsirolimus treatment did not induce apoptosis, but strongly obstructed cell proliferation. As expected, temsirolimus inhibited the cell count of all MPM cell lines tested. In contrast, Schedel et al (16) reported that temsirolimus significantly reduced cell viability and induced apoptosis and cell cycle arrest in bladder cancer and head and neck squamous cell carcinoma.
MPM is highly resistant to conventional chemotherapy. Cisplatin is one of the most effective chemotherapeutic agents against MPM but, if used alone, its response rate against MPM has been shown to be only $16.7 \%$, with a median survival time of 9.3 months (17). When used in combination with the multitargeted antifolate agent pemetrexed, the response rate increased significantly to $41.3 \%$ and the median survival time was significantly prolonged to 12.1 months; however, the difference was only 2.8 months. Therefore, the identification of new agents is warranted. In the present study, we evaluated the therapeutic efficacy of the combined treatment of temsirolimus and cisplatin in MPM cell lines. Combination treatment with temsirolimus and cisplatin inhibited the viability of all MPM cell lines more effectively than treatment with temsirolimus alone. Hence, a synergistic or additive effect for the combination treatment of temsirolimus and cisplatin can be hypothesized, in accordance with another report (10).

Rapidly proliferating tumors require an efficient blood supply to meet their nutritional needs; therefore, angiogenesis is essential for the growth and metastasis of tumors (18). VEGF is one of the most potent stimulators of angiogenesis, and high expression of VEGF is associated with intratumoral microvessel density and a poor prognosis in various types of carcinomas $(19,20)$. PDGF has also been shown to support growth, angiogenesis and stroma recruitment in various tumor types $(21,22)$. Del Bufalo et al (6) reported that temsirolimus may potently inhibit angiogenesis by multiple mechanisms: indirectly through transcriptional inhibition of hypoxia-stimulated, HIF- $1 \alpha$-dependent VEGF production as well as directly through inhibition of the endothelial cell functions involved in neoangiogenesis (e.g., growth factor-stimulated proliferation and morphogenesis). Other authors have reported that an mTOR inhibitor inhibits tumor growth by an antiangiogenic effect or by tumorspecific thrombosis associated with a decrease in VEGF production (23). In accordance with our previous studies $(24,25)$, tumor progression of Y-meso14 and EHMES-10 (human MPM cell lines), which expressed high levels of VEGF, was inhibited by bevacizumab (an anti-VEGF antibody) or E7080 (a multi-tyrosine kinase inhibitor) in vivo. In contrast, the tumor progression of MSTO-211H cells (which expressed low levels of VEGF) was not inhibited by treatment with bevacizumab. In the present study, we showed that temsirolimus strongly inhibited the production of VEGF in all four MPM cell lines tested. Temsirolimus is expected to inhibit the growth of VEGF-high-producing tumors (e.g., Y-meso14), due not only to an anticancer effect but also an antiangiogenic effect in vivo.

In summary, our results suggest that the mTOR inhibitor temsirolimus inhibits the proliferation of MPM cells, and strengthens the effect of platinum-based chemotherapy. The treatment effect resulted in dephosphorylation of the downstream proteins of the PI3K/Akt signaling pathway. In addition, the antiangiogenic effects may contribute substantially to the antitumor activity of tumors producing high levels of VEGF, such as in Y-meso 14 cells. Temsirolimus may be beneficial for a subset of MPM patients with high mTOR expression. We intend to investigate the effect of temsirolimus treatment in a MPM model in vivo. 


\section{References}

1. Ong ST and Vogelzang NJ: Chemotherapy in malignant pleural mesothelioma. A review. J Clin Oncol 14: 1007-1017, 1996.

2. Antman KH: Natural history and epidemiology of malignant mesothelioma. Chest 103: 373S-376S, 1993.

3. Aisner J. Current approach to malignant mesothelioma of the pleura. Chest 107: 332S-344S, 1995.

4. Schmelzle T and Hall MN: TOR, a central controller of cell growth. Cell 103: 253-262, 2000.

5. Grewe M, Gansauge F, Schmid RM, Adler G and Seufferlein T: Regulation of cell growth and cyclin D1 expression by the constitutively active FRAP-p70s6K pathway in human pancreatic cancer cells. Cancer Res 59: 3581-3587, 1999.

6. Del Bufalo D, Ciuffreda L, Trisciuoglio D, et al: Antiangiogenic potential of the mammalian target of rapamycin inhibitor temsirolimus. Cancer Res 66: 5549-5554, 2006.

7. Hudes G, Carducci M, Tomczak P, et al: Global ARCC Trial Temsirolimus, interferon alfa, or both for advanced renal-cell carcinoma. N Engl J Med 356: 2271-2281, 2007.

8. Chan S, Scheulen ME, Johnston S, et al: Phase II study of temsirolimus (CCI-779), a novel inhibitor of mTOR, in heavily pretreated patients with locally advanced or metastatic breast cancer. J Clin Oncol 23: 5314-5322, 2005.

9. Hartman ML, Esposito JM, Yeap BY and Sugarbaker DJ: Combined treatment with cisplatin and sirolimus to enhance cell death in human mesothelioma. J Thorac Cardiovasc Surg 5 1233-1240, 2010.

10. Hoda MA, Mohamed A, Ghanim B, et al: Temsirolimus inhibits malignant pleural mesothelioma growth in vitro and in vivo: synergism with chemotherapy. J Thorac Oncol 6: $852-863,2011$

11. Frost P, Moatamed F, Hoang B, et al: In vivo antitumor effects of the mTOR inhibitor CCI-779 against human multiple myeloma cells in a xenograft model. Blood 15: 4181-4187, 2004.

12. Green LM, Reade JL and Ware CF: Rapid colorimetric assay for cell viability: application to the quantitation of cytotoxic and growth inhibitory lymphokines. J Immunol Methods 70 257-268, 1984

13. Dobashi Y, Suzuki S, Sato E, Hamada Y, Yanagawa T and Ooi A EGFR-dependent and independent activation of Akt/mTOR cascade in bone and soft tissue tumors. Mod Pathol 22: 1328-1340, 2009.
14. Galanis E, Buckner JC, Maurer MJ, et al: Phase II trial of temsirolimus (CCI-779) in recurrent glioblastoma multiforme: a North Central Cancer Treatment Group Study. J Clin Oncol 23: 5294-5304, 2005

15. Jefferies HB, Fumagalli S, Dennis PB, Reinhard C, Pearson RB and Thomas G: Rapamycin suppresses 5'TOP mRNA translation through inhibition of p70s6k. EMBO J 16: 3693-3704, 1997.

16. Schedel F, Pries R, Thode B, et al: mTOR inhibitors show promising in vitro activity in bladder cancer and head and neck squamous cell carcinoma. Oncol Rep 25: 763-768, 2011.

17. Vogelzang NJ, Rusthoven JJ, Symanowski J, et al: Phase III study of pemetrexed in combination with cisplatin versus cisplatin alone in patients with malignant pleural mesothelioma. J Clin Oncol 21: 2636-2644, 2003.

18. Fidler IJ and Ellis LM: The implications of angiogenesis for the biology and therapy of cancer metastasis. Cell 79: 185-188, 1994.

19. Niedergethmann M, Hildenbrand R, Wostbrock B, et al: High expression of vascular endothelial growth factor predicts early recurrence and poor prognosis after curative resection for ductal adenocarcinoma of the pancreas. Pancreas 25: 122-129, 2002.

20. Takahashi Y, Kitadai Y, Bucana CD, Cleary KR and Ellis LM: Expression of vascular endothelial growth factor and its receptor, KDR, correlates with vascularity, metastasis, and proliferation of human colon cancer. Cancer Res 55: 3964-3968, 1995.

21. Ostman A and Heldin CH: PDGF receptors as targets in tumor treatment. Adv Cancer Res 97: 247-274, 2007.

22. Andrae J, Gallini R and Betsholtz C: Role of platelet-derived growth factors in physiology and medicine. Genes Dev 22: 1276-1312, 2008.

23. Guba M, Yezhelyev M, Eichhorn ME, et al: Rapamycin induces tumor-specific thrombosis via tissue factor in the presence of VEGF. Blood 105: 4463-4469, 2005.

24. Li Q, Yano S, Ogino H, et al: The therapeutic efficacy of antivascular endothelial growth factor antibody, bevacizumab, and pemetrexed against orthotopically implanted human pleural mesothelioma cells in severe combined immunodeficient mice. Clin Cancer Res 13: 5918-5925, 2007.

25. Ikuta K, Yano S, Trung VT, et al: E7080, a multi-tyrosine kinase inhibitor, suppresses the progression of malignant pleural mesothelioma with different proangiogenic cytokine production profiles. Clin Cancer Res 15: 7229-7237, 2009. 